\title{
Studies on Rubber Base Impression Materials (Part XXX) Discussions on the Setting Mechanism of Polysulfide Rubber as the Dental Impression Material, Chiefly viewed from the Variations of Viscosity and Molecular Weight
}

Part 10. Dynamic Properties of Polysulfide Rubber Products (II)

\author{
by
}

Setsuo HIGASHI, ${ }^{*}$ Shuii YASUDA, * Hiroshi KOBAYASHI,*

Kiyosato HIROI, ${ }^{*}$ Nobuaki OGAWA,* Hisashi TAKAMATSU* and

Yoshimi MIMURA*

\section{Introduction}

In part 9[1], it was made clear from the shapes of stress-strain curves that the behavior of the test materials were very similar to that of cross-linked rubber. Then in the present Part, in order to examine whether the polysulfide rubber is cross-linked or not from other viewpoints, the authors first of all measured rigidity at various temperatures by means of free torsion oscillation method.

On the other hand when a high-molecular substance in process of formation abruptly changes from viscous fluid into elastic gel, the substance under poly-condensation is soluble in some kind of solvent before getting to the gel point[2] but after passing the point, generally, it shows large resistivity against the solvent. Such a gelling phenomenon can be seen only when a space reticulated structure is formed, and is accordingly used for deciding whether a test material is a linear high-molecular substance or cross-linked high-molecular one. In the present Part, therefore, the dissolution state of cured products completely hardened by five hours heat treatment at $100^{\circ} \mathrm{C}$ was examined by making various solvents severally act on them.

\section{Materials and Experimental Procedures}

I. Measurement of the change of rigidity $G$ with temperature

1) Test materials and experimental method[3]

Four kinds of cured products No. 1 to No. 4 were prepared as test materials.

As shown in Fig. 174 a test piece was vertically suspended with the upper end fixed, and an inertia bar attached to the lower end was slightly vibrated about the vertical axis passing through the center of gravity of the bar so as to give the test piece torsion oscillation.

\footnotetext{
* 東節男, 安田周治, 小林博, 広井清智, 小川信昭, 高松久, 三村善美, Dept. of Dental Materials, Nihon Unlv. School of Dentistry, Tokyo (Director: Prof. Eetsuo Higashi).
} 


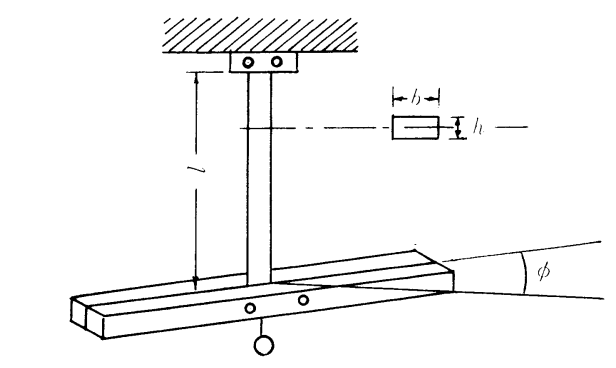

Fig. 174 Measurement arrangement of rigidity

(torsionally vibrating)

As the displacement of the bar from the equilibrium position is represented by angle $\phi$, it can be treated as 'degree of freedom' movement. Then by regarding the test material as an elastic body having viscosity changeable in proportion to the strain change with time, and by neglecting air resistance, the following kinetic equation can hold.

$$
I \frac{d^{2} \phi}{d t^{2}}+C \frac{d \phi}{d t}+K \phi=0
$$

$\mathbf{t}$, represents time, $\mathbf{I}$, the moment of inertia of the bar, $\mathbf{C}$, viscosity damping canstant of the test piece and $\mathbf{K}$, torsion strength.

In case of film-shape piece, if $\mathbf{h}$, represents its thickness, $\mathbf{b}$, the width and 1, the effective length, the following equation can be given:

$$
C=\frac{b h^{3}}{3 l} \eta, \quad K=\frac{b h^{3}}{3 l} G \quad \begin{array}{ll}
\eta: & \text { viscosity coefficient }(\text { poise })
\end{array}
$$

Oscillation synchronism can be given as follows:

$$
T=\frac{2 \pi}{\sqrt{K / I}}(\mathrm{sec})
$$

and by solving equation (1), G, can be represented as follows:

$$
\begin{aligned}
G & =\frac{12 \pi^{2} l I}{b h^{3} T^{2}} \\
& =\frac{12 l I \lambda}{b h^{3} T}
\end{aligned}
$$

G, in equation (2) is the observed value, and in case of film-shape test piece, it is necessary to make corrections for width and for torsion moment caused by tension on the film surface, $\delta=\mathrm{Wg} / \mathrm{bh}(\mathrm{W}=$ weight of the inertia bar, $\mathrm{g}=$ acceleration of gravity).

$$
G_{0}=\left(\frac{12 \pi^{2} l I}{b h^{3} T^{2}}-\frac{1}{4}\left(\frac{b}{h}\right)^{2} \sigma\right)\left(1-0.63 \frac{b}{h}\right)^{-1}
$$

Logarithmic decrement $\lambda[4]$ is:

$$
\lambda=\frac{C T}{4 I}=\pi^{2}\left(\frac{\eta}{T}\right)\left(\frac{1}{G}\right)
$$

and $\lambda_{0}$, the logarithmic decrement corresponding to $G_{0}$ is:

$$
\lambda_{0}=\pi^{2}\left(\frac{\eta}{T}\right)\left(\frac{1}{G_{0}}\right)
$$

Therefore, the following equation can be obtained: 


$$
\lambda\left(1-0.63 \frac{h}{b}\right)=\lambda_{0}-\frac{1}{4 G_{0}}\left(\frac{b}{h}\right)^{2} \sigma \lambda
$$

$\lambda_{0}$ as well as $G_{0}$ means the case having no tension.

In equation (6) $\eta / T$ is assumed to be constant. This assumption can be considered experimentally right if time is in secondunit order.

The dimensions of the test piece are: $b=1 \mathrm{~cm}, l=10 \mathrm{~cm}$ and $\mathrm{h} \doteqdot 0.1 \mathrm{~cm}$, and as for the inertia bar, $\mathrm{I}=966 \mathrm{~cm}^{2}$ and $\mathrm{W}=27.6 \mathrm{~g}$ (weight, including attachments)

Of the test materials, before and after 5 hours heat treatment at $100^{\circ} \mathrm{C}$, changes of rigidity with temperatures from $30^{\circ} \mathrm{C}$ to $140^{\circ} \mathrm{C}$ were measured. The rigidity of No. 1 test material not heat-treated was measured at each temperature from $-70^{\circ} \mathrm{C}$ to $+130^{\circ} \mathrm{C}$.

2) Experimental results

Rigidity-temperature curve, from $-70^{\circ} \mathrm{C}$ to $+130^{\circ} \mathrm{C}$, of No. 1 test material not heat-treated is given in Fig. 175, and its logarithmic decrement(\$)-temperature curve from $-70^{\circ} \mathrm{C}$ to $+130^{\circ} \mathrm{C}$ in Fig. 176 . Rigidity-temperature curves, from $30^{\circ} \mathrm{C}$ to $130^{\circ} \mathrm{C}$, of No. 1 test material, before and after heat-treatment are given to be compared with each other in Fig. 177, those of No. 2 in Fig. 178 those of No. 3 in Fig. 179 and those of No. 4 in Fig. 180.

3) Discussion

Fig. 175 the rigidity-temperature curve of No. 1 test material not heat-treated, which has neither plasticizer nor filler, indicates that glasstransition point exists at around $-50^{\circ} \mathrm{C}$. At $70^{\circ} \mathrm{C}-90^{\circ} \mathrm{C}$ rigidity increases slightly, and Fig. 176, the logarithmic decrement $(\lambda)$-temperature curve prepared for re-examination indicates that $\lambda \mathrm{ab}$ ruptly increases between $90^{\circ} \mathrm{C}$ and $100^{\circ} \mathrm{C}$. But the cause of this sudden increases of $\lambda$ could not be determined.

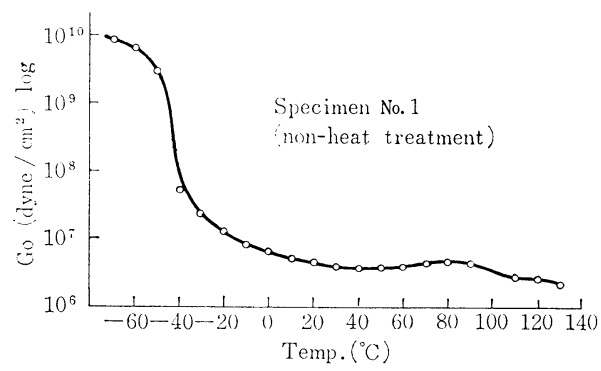

Fig. 175 Rigidity-temp. curve

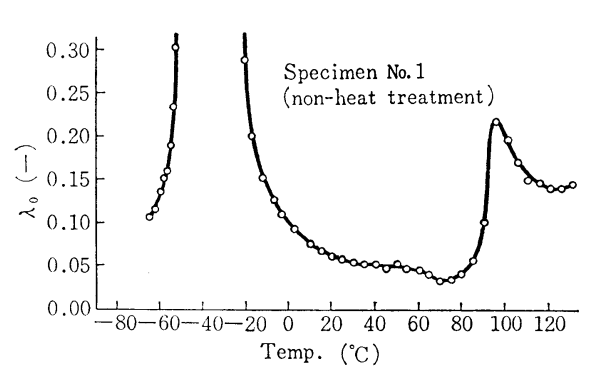

Fig. 176 log-attenuation factor $(\lambda)$-temp. curve

From the result of examination on rigidity-temperature curves given in Fig.177180 , it was made clear that generally rigidity of the test materials not heat-treated was low as compared with that of the heat-treated materials, and that the curves of the former showed tendencies to descend at comparatively low temperatures though gently. This is presumably due to the fact that the heat treatment made substances which until then remained unreacted in the test materials react and made rigidity high.

Rigidity-temperature curves shown in Fig. 175-180 indicate typical behavior of rubber, having their respective wide plateau ranges $0^{\circ} \mathrm{C}$ to $130^{\circ} \mathrm{C}$. Plateaus show them- 


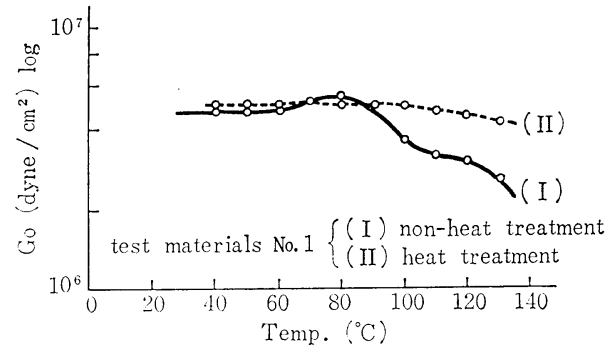

Fig. 177 Rigidity-temp. curves

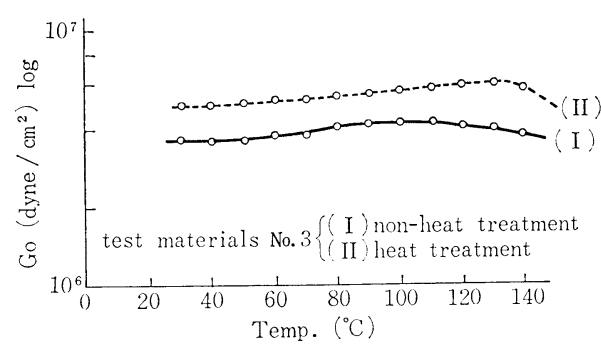

Fig. 179 Rigidity-temp. curves

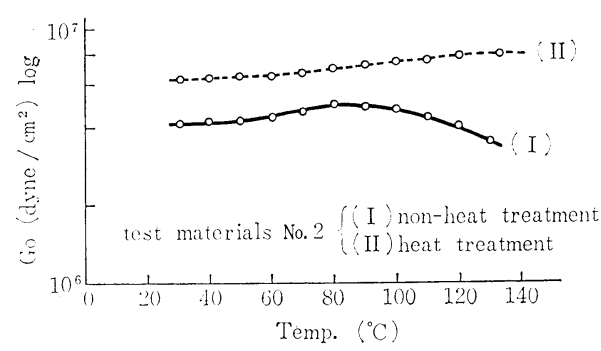

Fig. 178 Rigidity-temp. curves

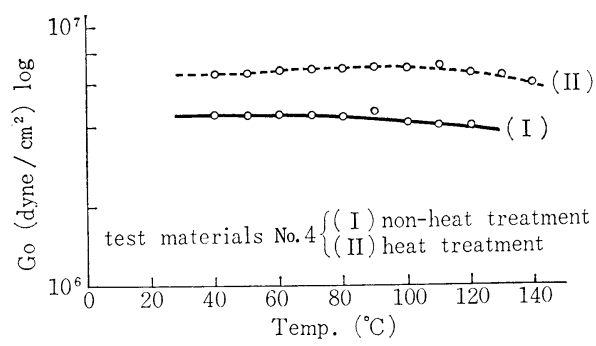

Fig. 180 Rigidity-temp. curves

selves higher in accordance with the rise of temperature. This is presumably due to the fact that the increase of rigidity by entropy elasticity effected by rise of temperature has overwhelmed the decrease of rigidity based upon the decrease of inner viscosity coefficient effected by rise of temperature. The behavior is very similar to that of crosslinked rubber.

\section{Dissolution test}

1) Test materials

Three kinds of polysulfide having different oxidizing agents were prepared and were used as test materials after five hours heat treatment at $100^{\circ} \mathrm{C}$. Their composition

Table 84

\begin{tabular}{|c|c|c|c|c|c|c|}
\hline Specimen & $\begin{array}{l}\text { Polysulfide } \\
\quad(\mathrm{M} . \mathrm{W} .=4000)\end{array}$ & Oxidizin & ig ag & & $\mathrm{D} \cdot \mathrm{B} \cdot \mathrm{P}$ & filler \\
\hline 2 & 100 & $\begin{array}{l}\mathrm{KMnO}_{4} \\
\mathrm{PbO}_{2}\end{array}$ & 2) & 4 & 20 & - \\
\hline 7 & 100 & $\mathrm{MnO}_{2}$ & $1\}$ & 20 & 20 & - \\
\hline 5 & 100 & $\mathrm{PbO}_{2}$ & & 20 & 20 & - \\
\hline
\end{tabular}

ratios are as follows:

Carbon tetrachloride, xylene, ehyl acetate, methyl ethyl ketone, tetrahydrofuran, dioxane, dimethyl formamide and cyclohexanone were used as solvents.

2) Experimental method

Thin pieces of the heat-treated test materials soaked in the various solvents at 
room temperature were left for 200 hours with shaking once a day, and their dissolution state was examined.

3) Experimental results

In carbon tetrachloride, xylene, ethyl acetate and methyl ethyl ketone, all the test pieces swelled, though comparatively not in a large degree, while in tetrahydrofuran, dioxane, dimethyl formamide and cyclohexanone, they swelled badly, and partially brownish precipitates were seen, though the original shapes of test pieces were kept almost unchanged. The viscosity of four kinds of polysulfide solutions with tetrahydrofuran and other strong solvents severally used was almost equivalent to that of respective solvents, and when small amounts of the solutions were severally added to methanol, only whitish trubidity appeared, which, different from thecases of general high-molecular solutions being added to nonsolvents, was not accompanied with gelatinous precipitates, as if it was the case of low-molucular substance.

Besides, even when the solutions were dried on a glass plate they would not change into film but viscous liquid. The swelled test films would not dissolve any more even in the brand-new strong solvents.

4) Discussion

Thin pieces of polysulfide rubber with lead peroxide, manganese dioxide and potassium permanganate respectively used as curing agents, hardened completely by 5 hours heat-treatment, were soaked in various solvents for a long time and their desolution state was examined. As the result it became clear that the test materials were not soluble in carbon tetrachloride, xylene, ethyl acetate and methyl ethyl ketone, but in tetrahydrofuran, dioxane, dimethyl formamide and cyclohexanone they swelled very badly and partially low-molecular substances were recognized to be dissolved out, though the original shapes of the test pieces were kept unchanged. From these results it can be presumed that these kinds of polysulfide rubber completely hardened have loose reticulated structures, unrelated to the kind of oxidizing agent.

\section{Summary}

In Part 9 and the present Part the authors examined dynamic properties and inner structures of polysulfide rubber products by dissolution test as well as by preparing stress relaxation curves, stress-strain curves and rigidity-temperature curves by means of free torsion oscillation method. The results can be summarized as follows:

1) The examination on stress relaxation at $30^{\circ} \mathrm{C}$ showed that the cured products having manganese group oxidizing agents had moduli of elasticity higher than those of the products having lead peroxide as oxidizing agent, though they showed a slight tendency to decrease almost rectilinearly.

The examination on stress relaxation at $100^{\circ} \mathrm{C}$ revealed that the modull of elasticity showed a tendency to decrease from around $10^{2} \mathrm{sec}$. This phenomenon is considered to indicate an intermediate behavior between polyisobutylene, non-cross-linked rubber, and cross-linked polysulfide rubber. Furthermore, the stress at $100^{\circ} \mathrm{C}$ intermittently measured for three hours showed a slight tendency to increase with the lapse of time, but the difference being hardly considered to be of special significance, no conclusive evidence was given to show that the strees relaxation was caused by chemical action. 
2) By fixed-velocity extension tests, stress-strain curves were prepared and $3 \mathrm{~S} /$ $(\alpha-\alpha-2)$ vs. $\alpha-1$ was plotted. As the result it was made clear that the curves became almost rectilinear showing typical behavior of cross-linked rubber, which could be represented by Mooney-Rivlin's formula.

3) According to rigidity-temperature curves prepared by means of free torsion oscillation method, the test materials not heat-treated had low rigidity as compared with the heat-treated materials, and the curves showed descending tendencies at lower temperatures though gently. This is presumably due to the fact that the heat-treatment made substances which until then remained unreacted in the test materials react and made rigidity high.

All rigidity-temperature curves having wide plateau ranges from $0^{\circ} \mathrm{C}$ to $130^{\circ} \mathrm{C}$ showed typical behavior of cross-linked rubber.

4) To examine whether a test material is soluble in solvents is one of the effective method to determine the test material to be linear high-molecular substance or cross-linked high-molecular one. The dissolution state of cured products completely hardened by 5 hours heat-treatment at $100^{\circ} \mathrm{C}$ was therefore examined by using various solvents and as a result it was made clear that the test pieces swelled badly in tetrahydrofuran and other strong solvents, and though partially brownish precipitates were seen, the original shapes of test pieces were kept unchanged. From this result it was presumed that these kinds of polysulfide rubber were of loose-reticulated structure.

\section{Conclusion}

Judging from the results of these experiments, it can be concluded that these kinds of polysulfide rubber, having wide plateau ranges from $0^{\circ} \mathrm{C}$ to $130^{\circ} \mathrm{C}$ and moduli of elasticity about $1 \times 10^{7} \mathrm{dyne} / \mathrm{cm}^{2}$, and whose low-molecular substances being recognized to be dissolved out at dissolution tests, have very long molecular structures, loosely cross-linked.

\section{Reference}

[1] S. Yasuda, H. Yamada, K. Kuroki, and U. Oshiro: J. of the Japan Society for Dental Apparatus and Materials, Vol. 6, No. 11, (1965).

[2] P. J. FloRY: High Polymer Chemistry; Translated into Japanese by S. Oka \& K. Kanamaru, Maruzen, Tokyo, 45, (1960).

[3] Y. Inoue, Y. OвAтA: J. of the Chemical Society of Japan; Industrial Chemistry Section, Vol. 62, 84, (1959).

[4] S. OnOGI: Theory of rheology; p. 180, (1962). 